ISSN 2075-4701

www.mdpi.com/journal/metals/

Article

\title{
Molding of Aluminum Foams by Using Hot Powder Extrusion
}

\author{
Masanori Shiomi * and Yoshitaka Tanino \\ Department of Innovative Mechanical Engineering, Faculty of Global Engineering, \\ Kogakuin University, Inume, Hachioji, Tokyo 193-0802, Japan; E-Mail: msandrog1@gmail.com \\ * Author to whom correspondence should be addressed; E-Mail: shiomi@cc.kogakuin.ac.jp; \\ Tel./Fax: +81-42-628-2429.
}

Received: 29 March 2012; in revised form: 9 May 2012 / Accepted: 25 May 2012 /

Published: 5 June 2012

\begin{abstract}
In order to form aluminum foams directly from powder, a combined process of hot powder extrusion and molding is proposed. Aluminum powder mixed with a foaming agent is extruded into the mold through the die heated to a temperature higher than the melting point, and the mold is filled with the aluminum foam. When a stainless steel pipe is used for a simple mold, an aluminum foam bar is obtained of which the relative density varies between 0.2 and 0.3 . The molding of aluminum foam by using three types of mold shape shows the influence of gravity and friction. The effect of gravity is significant when a large step exists at the connection between the mold inlet and the die outlet, and friction is dominant in cases where foam is mold in a narrow space.
\end{abstract}

Keywords: porous metals; aluminum foam; hot powder extrusion; molding; density; gravity; friction

\section{Introduction}

Many fabricating processes of metal foams have been developed [1,2]. Among them, the practical processes for producing metal foams are classified into two routes: melt route and powder metallurgy. In the melt route, blocks of aluminum foam with a regular shape are commercially manufactured in batch operations, and the mechanical properties of the produced foams have been reported $[3,4]$. Sheets of aluminum foam are continuously fabricated by drawing out from the surface of the molten metal injected bubbles of gas [5]. The melt route is suitable for mass production of metal foams with a simple shape. 
In the powder metallurgy route, metallic powder is mixed with a blowing agent and it is compacted to form a foamable precursor. Then, the precursor is heated and formed to foam in a furnace [6]. The advantage of this route is that the precursor can expand in a mold and foam with a complicated shape can be made by mold filling. However, the powder metallurgy route requires the preparation of a precursor to produce the foam. It is desirable to produce metal foams from powder in a short-time process for manufacturing automotive parts.

In this paper, a method for fabricating aluminum foams from powder including a foaming agent is proposed for light-weight automobile structures. Aluminum powder mixed with a blowing agent is heated and extruded into a mold through the heated die, and the extruded aluminum expands and fills the mold. The cylindrical aluminum foam is produced by using a pipe as a mold, and the distribution of the density within the foam is measured. To examine the molding process, three molds with different shapes are filled with aluminum foam and the volume ratio of the foam to the mold is measured.

\section{Experimental Equipment}

Figure 1 shows the experimental equipment for molding of aluminum foams by using hot powder extrusion [7]. Aluminum alloy powder (A6061) mixed with $\mathrm{TiH}_{2}$ powder as a foaming agent is poured into the container of the hot powder extruder and it is compacted in a room temperature at a pressure of $100 \mathrm{MPa}$. The container is heated to $420{ }^{\circ} \mathrm{C}$ for hot extrusion of aluminum, and then the aluminum powder with $\mathrm{TiH}_{2}$ powder is extruded into the heated die for foaming the aluminum compact. In the molding part of aluminum foam, the die for foaming of the compact is heated to a temperature higher than the liquidus point $\left(652^{\circ} \mathrm{C}\right)$ of the aluminum alloy. The extruded aluminum compact goes into the heated die and starts foaming in the vicinity of the die exit. Then, the mold is filled with the aluminum foam.

The die for foaming of the aluminum compact is heated by an induction heater, and the temperature of the die is controlled so as to be constant. The outlet diameter of the die is smaller than that of the inlet, so that the aluminum compact comes into contact with the die and is heated due to heat conduction.

Figure 1. Experimental equipment for molding of aluminum foam from powder.

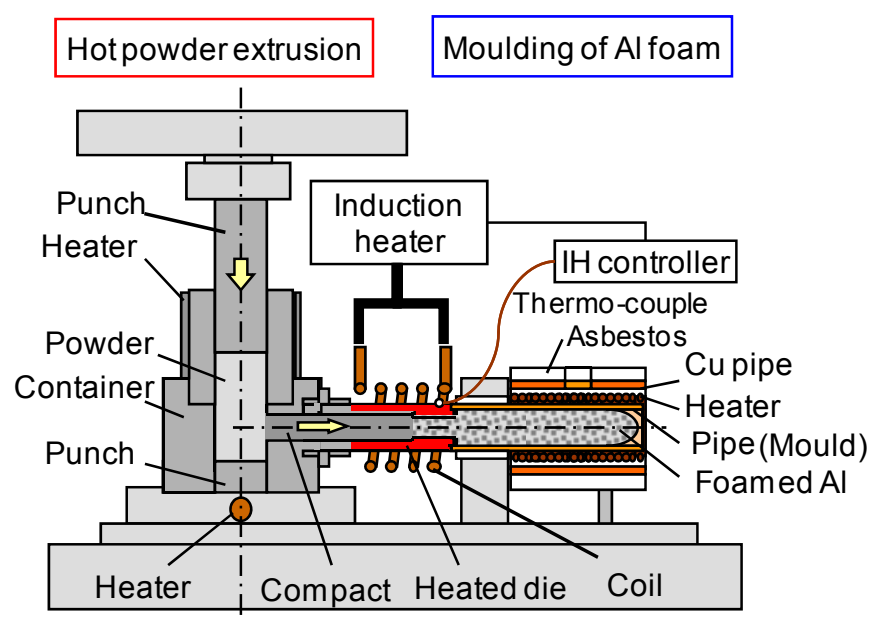


The temperature of the container was measured on the surface and hot powder extrusion was carried out at $420^{\circ} \mathrm{C}$. The inlet and outlet diameters of the container were $30 \mathrm{~mm}$ and $16.5 \mathrm{~mm}$, respectively, so that the extrusion ratio was 3.3. The relative density of the aluminum compact reached more than 0.99.

A stainless steel pipe was used as a mold for simple shape forming at the first step. The dimensions of the pipe were $25 \mathrm{~mm}$ in inner diameter, $100 \mathrm{~mm}$ in length and $1.5 \mathrm{~mm}$ in thickness. The pipe mold was covered with a heater, a copper pipe and a heat insulator (ceramic fiber). The copper pipe had a hole of $10 \mathrm{~mm}$ in diameter at the centre, and the pipe mold was heated with the heater and cooled by air blowing into the space between the heater and the copper pipe. Table 1 shows the chemical compositions of the aluminum alloy (A6061).

Table 1. Chemical compositions of aluminum powder A6061 (mass \%).

\begin{tabular}{cccccc}
\hline $\mathbf{M g}$ & $\mathbf{S i}$ & $\mathbf{C u}$ & $\mathbf{F e}$ & $\mathbf{C r}$ & $\mathbf{A l}$ \\
\hline 1.04 & 0.61 & 0.28 & 0.23 & 0.21 & Balance \\
\hline
\end{tabular}

\section{Molding of Al Foam}

\subsection{Pipe Mold}

Table 2 shows the experimental conditions of extrusion and molding. The punch stroke of $18 \mathrm{~mm}$ was determined from the volume calculation, in which solid aluminum extruded from the die would expand and fill the mold perfectly, and the relative density of aluminum foam would be 0.25 . In the experimental processes, aluminum powder with a foaming agent was poured into the container and extruded into the die. The die was heated to a temperature higher than the liquidus point of the aluminum alloy $\left(652{ }^{\circ} \mathrm{C}\right)$, and the overflow of aluminum foam from the heated die due to expansion was removed. Then, the pipe mold was attached to the cooled die and heated again for molding. After the preparation, the experiment for molding the aluminum foam into the pipe mold was carried out.

Table 2. Experimental condition for pipe molding of Al foam.

\begin{tabular}{cc}
\hline \multicolumn{2}{c}{ Parameter } \\
\hline Aluminum powder & $\mathrm{A} 6061$ \\
Foaming agent & $\mathrm{TiH}_{2}$ \\
Container temperature ${ }^{\circ} \mathrm{C}$ & 420 \\
Punch speed $\mathrm{mm} / \mathrm{s}$ & 0.45 \\
Extrusion ratio & 3.3 \\
Punch stroke $\mathrm{mm}$ & 18 \\
Die temperature ${ }^{\circ} \mathrm{C}$ & 760 \\
\hline
\end{tabular}

The cross-sectional shapes of the aluminum foams molded into the pipe are shown in Figure 2. When the pipe mold was cooled by air blowing after forming, it took 40 seconds until the mold temperature decreased to the solidus temperature of the aluminum alloy $\left(572{ }^{\circ} \mathrm{C}\right)$, which was the minimum cooling time for the experimental equipment. The aluminum foam filled the pipe and overflowed from the pipe end. The relative density of the whole foam is 0.24 , and the range of the cell size is not large. When the aluminum foam was cooled naturally without blowing air, the cell size at the centre of the foam became larger than in other parts, due to coalescence. The central part of the 
mold is not cooled quickly because of the heat insulator around the mold. The end part of the foam is condensed at the mold inlet. Although the punch ceases pushing the powder into the container of the hot powder extruder, foaming of the aluminum compact in the die does not stop at the same time. The aluminum compact in the die still expands after forming and the foam around the mold inlet is condensed. The density of the foam is in a wide range, although the relative density of the whole foam is 0.26 . It is important to control the temperature of the mold and the die for the density distribution of the molded foam. To obtain more uniform cell size of the foam, the aluminum foam should be cooled rapidly after forming.

Figure 2. Cross-sectional shape of Al foam molded into pipe: (a) Cooling with blowing air (cooling time: $40 \mathrm{~s}$, relative density: 0.24, length: $119 \mathrm{~mm}$ ); (b) Cooling without blowing air (cooling time: $125 \mathrm{~s}$, relative density: 0.26, length: $110 \mathrm{~mm}$ ).

(a)

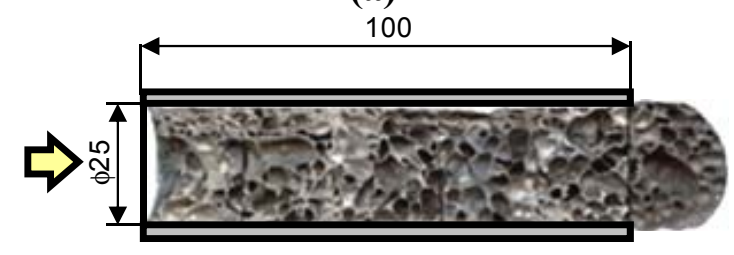

(b)

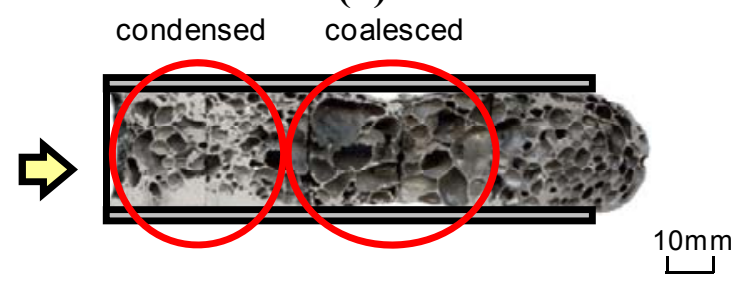

To measure the density distribution within the aluminum foams, the foams were cut at every $20 \mathrm{~mm}$ from the end in the longitudinal direction and the densities were obtained by Archimedes method. Figure 3 shows the density distribution of the foam produced directly from powder for different cooling time. The measured relative densities are plotted at the centre position of the cut portion. When the cooling time is $125 \mathrm{~s}$, the relative density at the centre of the foam is very low. On the other hand, the relative densities at the end parts are very high because of gas leakage and condensation with the overflowed foam from the die. In the case of $40 \mathrm{~s}$ of cooling time, the relative density of the foam is in a range of 0.2 to 0.3 and the average relative density is 0.24 . The density distribution within the foam fabricated by rapid cooling becomes more uniform than that by natural cooling. It is considered that the high cooling speed after forming is important to form aluminum foam with a small range of density distribution within the foam.

Figure 3. Distribution of relative density within $\mathrm{Al}$ foam.

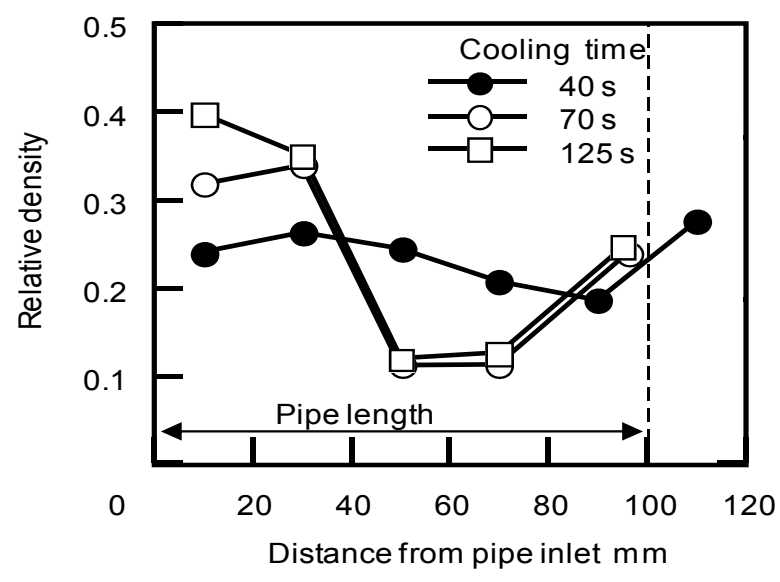




\subsection{Effect of Mold Shape}

To examine the effect of mold dimension, three molds with different shapes are filled with aluminum foam and the volume ratios of the foams to the mold are measured.

Figure 4 shows the shape and size of the molds. One side of the mold was covered by a lid and the other side was connected to the die for foaming of the aluminum precursor. The dimensions of the molds inside were 22, 16, 10 in diameter and 10,20, 50 in height, respectively. The volumes of mold inside were almost the same, and the aspect ratios of height to diameter of mold, H/D, varied from 0.45 to 5 . The diameter of the die outlet (Dout), was $9 \mathrm{~mm}$ in the experiment. The molds and die were made of stainless steel.

Figure 4. Shape and size of mold.
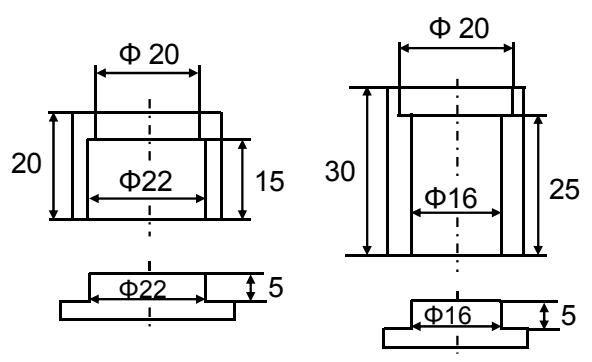

$$
\begin{aligned}
& H / D=0.45 \\
& (H=10, D=22)
\end{aligned}
$$

$H / D=1.25$
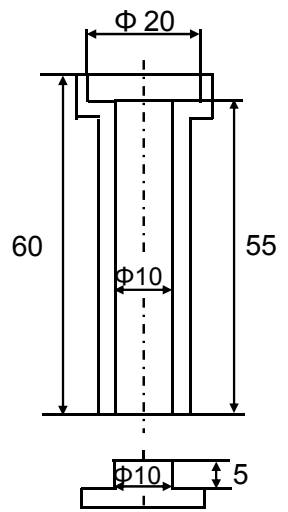

$H / D=5$

$(H=50, D=10)$
Mould inside

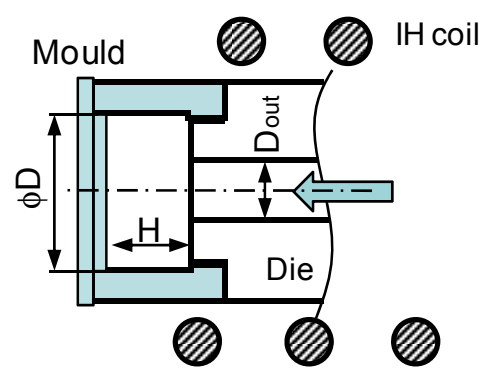
$(H=20, D=16)$ $\mathrm{H}$ : Height D: Diameter

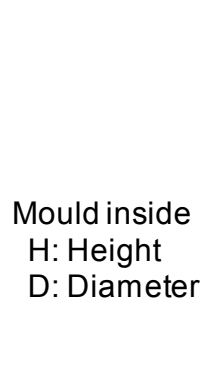

Figure 5 shows the volume ratio of the aluminum foam to the mold inside for different aspect ratios. When the aspect ratio of the mold, H/D, is 1.25 , the volume fraction of the mold filled with the foam is 0.76 . When the aspect ratios are 0.45 and 5 , the volume ratios of the foam to the mold become 0.64 and 0.39 , respectively.

Figure 5. Relationship between volume ratio of Al foam to mold inside and aspect ratio of mold.

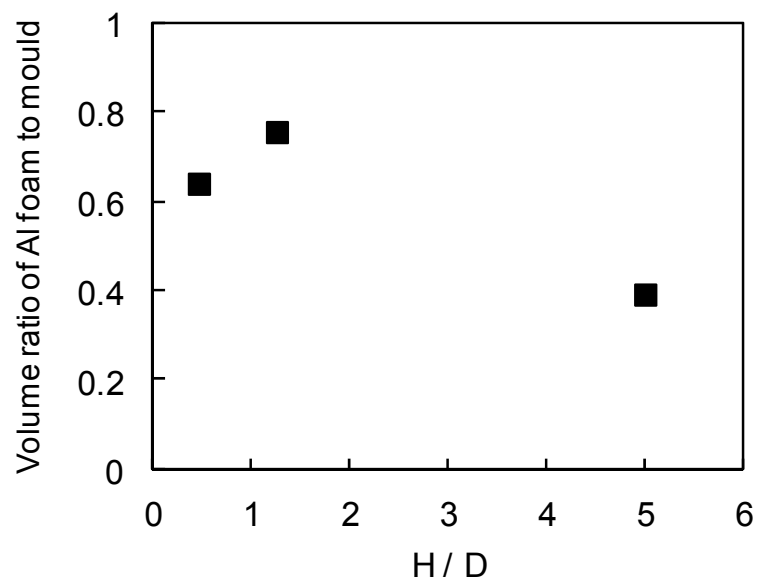

The shape of the aluminum foam in the mold is shown in Figure 6. When the aspect ratio of the mold is small: $\mathrm{H} / \mathrm{D}=0.45$, the difference of diameter between the mold inlet and the die outlet becomes large. 
The aluminum foam extruded from the die outlet flows down the level at the mold inlet, and it does not expand enough in the mold due to gravity and gas leak. When the aspect ratio of the mold is large, the diameter of the mold inlet is almost the same as that of the die outlet. Frictional force between the mold and the foam expanding in the mold becomes large, and the foam hardly flows through the mold. It is considered that there is an appropriate relation of size between the mold and the die.

Figure 6. Shape of $\mathrm{Al}$ foam in mold for different aspect ratio $\mathrm{H} / \mathrm{D}$ : (a) $\mathrm{H} / \mathrm{D}=0.45$;

(b) $\mathrm{H} / \mathrm{D}=1.25$.

(a)

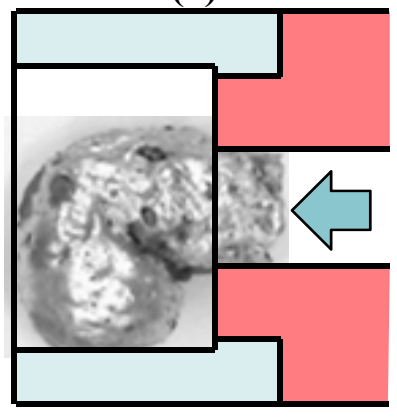

(b)

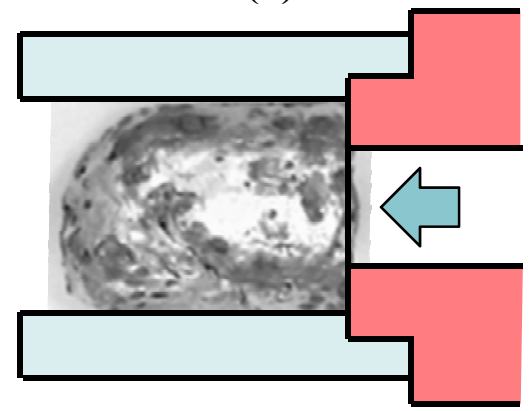

The influence of the diameter ratio of the mold inlet and the die outlet, D/Dout, on the volume ratio of the foam to the mold is shown in Figure 7. When D/Dout is large, there is a large step at the connection between the mold and the die, so that the effect of gravity on the molding of foam cannot be ignored. When $\mathrm{D} /$ Dout is close to 1 , the molding of foam is not successful due to friction. The range of $\mathrm{D} /$ Dout from 1.5 to 2 is considered to be appropriate in this experiment.

Figure 7. Influence of diameter ratio of mold inlet and die outlet on volume ratio of foam.

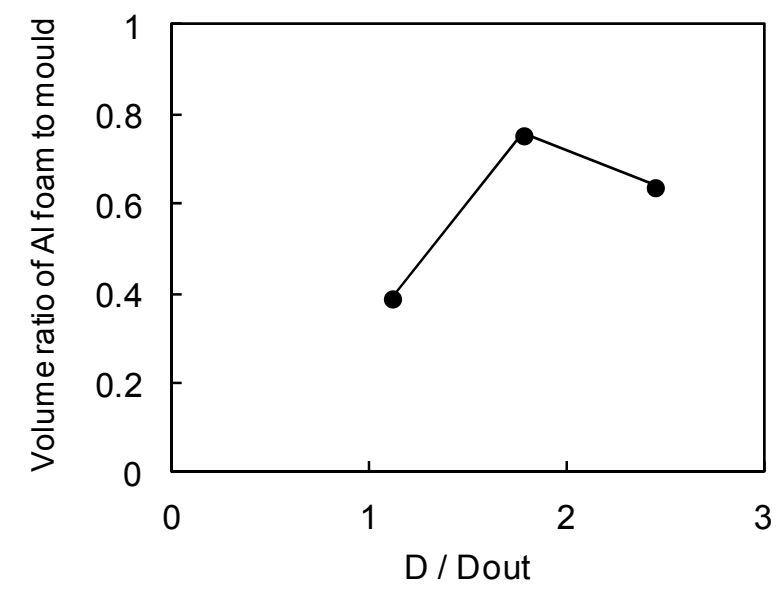

\section{Conclusions}

In order to produce aluminum foams directly from powder, the combined process of hot powder extrusion and molding was proposed. The A6061 aluminum powder mixed with $\mathrm{TiH}_{2}$ powder was extruded into the mold through the die heated to a temperature higher than the melting point, and the mold was filled with the aluminum foam. The molding of the aluminum foam into the pipe was carried out, and the distribution of relative density within the aluminum foam was in a range of 0.2 to 0.3 . 
Three molds with different shapes were filled with the foam, and the volume ratio of the foam to the mold was examined. The influence of gravity and friction on the molding of foam was found.

\section{References}

1. Ashby, M.F.; Evans, A.; Fleck, N.A.; Gibson, L.J.; Hutchinson, J.W.; Wadley, H.N.G. Metal Foams: A Design Guide; Butterworth-Heinemann: Oxford, UK, 2000; pp. 6-23.

2. Banhart, J. Manufacture, characterisation and application of cellular metals and metal foams. Prog. Mater. Sci. 2001, 46, 559-632.

3. Akiyama, S.; Ueno, H.; Imagama, K.; Kitahara, A.; Nagata, S.; Morimoto, K.; Nishikawa, T.; Itoh, M. Foamed Metal and Method of Producing Same. U.S. Patent 4,713,277, 15 December 1987.

4. Miyoshi, T.; Itoh, M.; Akiyama, S.; Kitahara, A. ALPORAS aluminum foam: Production process, properties and applications. Adv. Eng. Mater. 2000, 2, 179-183.

5. Jin, I.; Kenny, L.D.; Sang, H. Method of Producing Lightweight Foamed Metal. U.S. Patent 4,973,358, 27 November 1990.

6. Baumgärtner, F.; Duarte, I.; Banhart, J. Industrialization of powder compact foaming process. $A d v$. Eng. Mater. 2000, 2, 168-174.

7. Shiomi, M.; Imagama, S.; Osakada, K.; Matsumoto, R. Fabrication of aluminium foams from powder by hot extrusion and foaming. J. Mater. Proc. Technol. 2010, 210, 1203-1208.

(C) 2012 by the authors; licensee MDPI, Basel, Switzerland. This article is an open access article distributed under the terms and conditions of the Creative Commons Attribution license (http://creativecommons.org/licenses/by/3.0/). 